\title{
Evaluation of absorption characteristics for corrugated fiberboard using design of experiment approach
}

\author{
Chien-Chih Wang ${ }^{\mathrm{a}^{*}}$, Hsin-Tzu Chang ${ }^{\mathrm{a}}$, Chin-Hua Chen ${ }^{\mathrm{b}}$ \\ ${ }^{a}$ Department of Industrial Engineering and Management, Ming Chi University of Technology, New Taipei City, Taiwan \\ ${ }^{\mathrm{b}}$ Department of Industrial Engineering and Management, Yuan Ze University, Chung Li, Taiwan \\ *Corresponding Author: ieccwang@mail.mcut.edu.tw
}

\begin{abstract}
In this paper, proposed an experimental design framework based on drop test machine to collect data to establish a regression model. The analysis results show that the static stress, the drop height and the thickness of the cushioning material are the key variables of the impact strength. The prediction regression model of impact strength is $\mathrm{R}^{2}=$ 96.1\%. The resulting pattern can replace the current dynamic buffer curve.
\end{abstract}

Keywords: corrugated board, dynamic buffer curve, static stress, drop test, cushion design.

\section{Introduction}

There are many uncertain factors in product delivery. In order to make the goods in the logistics process meet the quality of customers, the appropriate buffer packaging must be given. Ensuring the complete arrival of products at the destination is the key to the quality of logistics services [1][2]. Packaging belongs to external quality cost. Although it is essential, it is not required by customers after all. Therefore, how to achieve industrial and reasonable packaging design is an important issue. Foamed plastic materials are often listed as the preferred buffer packaging materials by packaging designers. However, with the rise of environmental awareness, some countries have legislated and regulated the use of foamed plastic materials [3]. The corrugated board has the environmental protection characteristics of recycling and reuse and is gradually favored by manufacturers on the packaging buffer [4-7].

At the stage of packaging design, it is necessary to master the buffering characteristics of buffering materials, mainly in the hope of obtaining shock absorption and vibration transmission characteristics, as a basis for design.
The shock absorption characteristics of buffer material can be expressed by dynamic buffer curve. This curve is the impact strength (maximum acceleration) of specific buffer material of a specific thickness and a specific height under different static stresses. The dynamic buffering curve is essential information for buffering packaging design, which can determine the thickness and area of buffering material in the early stage of design. However, because the corrugated board is a composite structural material made of multi-layer kraft paper and corrugated core paper, each layer often changes due to cost or other factors, so there are a variety of permutations and combinations. According to the existing buffer material evaluation method to obtain the dynamic buffer curve is not only a time-consuming, labor-consuming and cost-consuming project but also because the test method cannot be close to the original packaging, the results obtained will lead to excessive packaging.

In practice, methods to establish a dynamic buffer curve include ASTM D 1596 for Foam in thick plate material (3) and ASTM D 4168 for Foam in Place [8-10]. However, there is no dynamic buffering curve test method for laminated corrugated buffering materials. In this study, a set of test procedures to replace the dynamic buffering curve was developed by using the falling test machine with a lower purchase cost. The in-package method based on experiment design technique was used to perform the dynamic buffering test of the laminated corrugated board to collect experimental data. Then, the ANOVA used to find out the optimal regression model of key factors and impact strength. Through the established model, the packaging designer can calculate the buffering effect under different design conditions in advance, to complete the appropriate packaging design in line with customer requirements. The advantage of the proposed method is that there is no need to 
re-test for a specific combination of design conditions to establish a dynamic buffer curve.

\section{Research Method}

The research was carried out in the laboratory of the cooperative manufacturer, and the equipment used included the falling test machine (Figure 1), accelerometer and signal processing software. The lansmont pdt-56ed falling test machine was used, and the height range of falling test was $30.0 \sim 182.9 \mathrm{~cm}$. Maximum sample weight: $56 \mathrm{~kg}$; The surface shall fall within 2 degrees, in line with CNS 2999, ASTM d-775 and ISO 2248 and other falling test standards. ICP Model 356A11 piezoelectric triaxial accelerometer was used, with the weight of $4 \mathrm{~g}$, size of 0.4 in * 0.4 in * 0.4 in, measurement range of plus or minus $500 \mathrm{G}$ 's, sensitivity of $10 \mathrm{mv} / \mathrm{g}$, frequency range: $2-7000 \mathrm{~Hz}$ (X, Y-axis), 2-10000 $\mathrm{Hz}$ ( $\mathrm{Z}$ axis). Lansmont TP3 signal processing software was used. The filtering frequency was set to $330 \mathrm{~Hz}$, and the waveform was the semi-sine wave

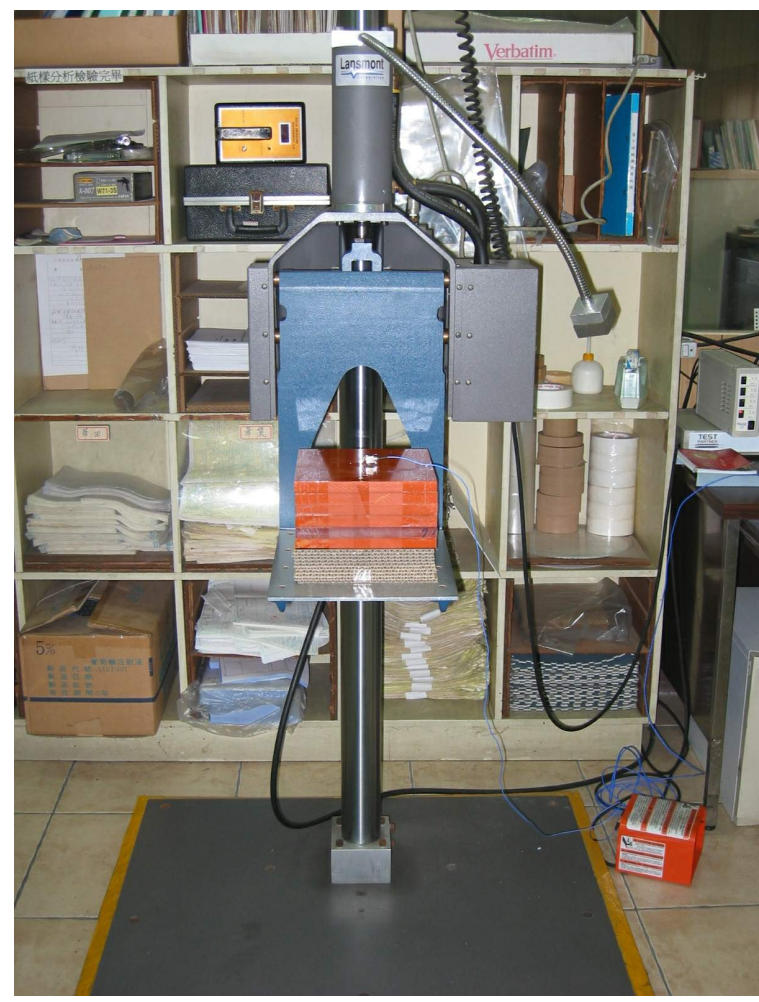

Figure 1. Experiment instruments of the falling test machine

This study proposes a three-stage procedure to experiment. The first stage is for sample making and experimental environment setting, and the second stage is for falling test data collection based on the designed experiment [11-12]. In the third stage, the in-package experiment was carried out to establish the prediction model. The steps are as follows:

- Step 1-1 sample production: corrugated board required for the test is produced by corrugated board machine, cut into $20 \mathrm{~cm} * 20 \mathrm{~cm}$ by trimming machine, and then stick into the sample according to the required thickness of each treatment to connect agents.

- Step 1-2 setting up the experimental environment: according to the pretreatment provisions of CNS 13190 packaging goods test, the sample shall be placed in the specified environmental conditions for at least 24 hours before the test. The environmental conditions set in this experiment were 20 degrees temperature, $50 \%$ relative humidity and $80 \%$, and the pretreatment time was set as 24 hours.

- Step 2-1 design the drop experiment: $2 \mathrm{k}$ factor design was used to conduct the screening experiment. Firstly, the factors mentioned in the literature and the practical situation were discussed, and the preliminary factor selection was completed. Then, considering the actual situation of data collection, the factor experiment of $2 \mathrm{k}$ set area was designed to perform the sample drop test, and the impact strength was recorded.

- Step 2-2 carry out falling test: according to the test sequence designed by step2-1, place the sample of step1-1,1-2 on the cantilever of the falling test machine, Step on the pedal of the falling test machine to make the sample fall, record the process data and draw the curve of impact time and acceleration, and the maximum acceleration is the impact intensity.

- Step 3-1 design in-package experiment: use factor design to conduct modeling experiment with the key factors and falling height obtained by step2-1 analysis. Control factors and environmental parameters should also be set before the experiment.

- Step 3-2 in-package test: the in-package test method was adopted for the actual packaging test. Laminated corrugated board sample, test box (simulation product) and filled corrugated board are packed into the corrugated box in sequence to become a complete packaging sample. A complete sample was used to perform a drop test with a drop tester, and the impact time and acceleration curves were generated to measure the impact strength. 


\section{Case study and analysis}

This case study is based on the corrugated board and equipment provided by Yuen Foong Yu Paper Mfg. in Taiwan. Firstly, the influencing factors of impact absorption characteristics of the laminated corrugated board include corrugated height, kraft paper thickness, the proportion of recycled slurry, corrugated board hardness, buffer material thickness, humidity, static stress, and falling height. The factors mentioned above are reviewed one by one before the experimental design to determine the screening factors and their levels. The experimental factors and levels selected after the review are described below.

- Fixed factor: since the falling height and static stress (product weight/buffer area) are the main parameters in the design of buffer packaging, which shall be determined according to the requirements of the product and customer, the fixed factor is set in the screening test. The height of the fall is set to $76.2 \mathrm{~cm}$ (30 inches). The static stress is $14 \mathrm{~g} / \mathrm{cm} 2$. (solid electric board weighing $5.6 \mathrm{~kg}$ was used as the simulated product, and the length and width of corrugated board buffer material were $20 \mathrm{~cm})$.

- Blocking factors: since the experiment could not be completed in one day, days and relative humidity were taken as the aggregation factor

- Main factors: the four main factors and the level were arranged as shown in table 1.

Table 1. Main factors and level setting

\begin{tabular}{|l|c|c|c|}
\hline \multirow{2}{*}{ Factor } & \multirow{2}{*}{ Code } & \multicolumn{2}{|c|}{ Level } \\
\cline { 3 - 4 } & & -1 & 1 \\
\hline Caliper (Liner) & A & $0.186 \mathrm{~mm}$ & $0.387 \mathrm{~mm}$ \\
\hline Flute Height & $\mathrm{B}$ & $2.7 \mathrm{~mm}$ & $4.7 \mathrm{~mm}$ \\
\hline Cushion thickness & $\mathrm{C}$ & $4-\mathrm{ply}$ & $10-\mathrm{ply}$ \\
\hline Basis Weight & $\mathrm{D}$ & $100 \mathrm{~g} / \mathrm{m} 2$ & $180 \mathrm{~g} / \mathrm{m} 2$ \\
\hline
\end{tabular}

Based on the configuration of experimental factors, this study used a $2^{4}$-factorial design. In order to reduce the experimental error, 10 repetitions were set for a total of 160 experiments. During the experiment, two blocking factors were considered, so the whole experiment was divided into four blocks, and the experimental order within the block was completely random. The experimental resolution is $\mathrm{V}$. Figure 2 shows the experimental design information. The response is the maximum acceleration ( $\mathrm{G}$ value, impact strength) measured by the acceleration fixed on the product during the impact.

Full Factorial Design

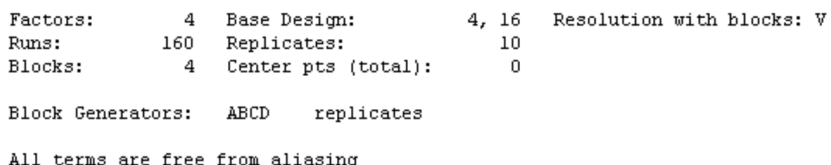

Figure 2. Design experiment information

Perform data analysis after completing the experiment according to the designed experiment. Firstly, ANOVA analysis was applied to find out the important factors. The results showed that the $\mathrm{P}$ values of factors $\mathrm{B}, \mathrm{C}, \mathrm{BC}, \mathrm{BD}$, $\mathrm{CD}, \mathrm{ABC}, \mathrm{ACD}$, and $\mathrm{BCD}$ were less than 0.05 , which was expressed as a significant factor. According to ANOVA analysis, the blocking factor is not significant, and the subsequent analysis incorporated all non-significant factors into the error terms. Next, the residual analysis of the model check is performed, and the result is shown in Fig. 3.

Weighted least squares regression was adopted for data transformation. After data transformation, data analysis was conducted again. The results showed that, with the error of type 1 being 0.05 , factors $\mathrm{B}, \mathrm{C}, \mathrm{BC}, \mathrm{BD}, \mathrm{CD}, \mathrm{ABC}, \mathrm{ACD}$, and $\mathrm{BCD}$ were significant factors. Finally, the residual model analysis was carried out on the transformed model. According to figure 4, the data were consistent with normality, homogeneity of variance and independence, so the model was appropriate. From Fig. 3, the predicted value and the residual relationship graph (upper right corner), it is seen that the graph gradually enlarges from left to right, which obviously does not conform to the assumption of uniform Using ANOVA, so data transformation must be performed. Weighted least squares regression was adopted for data transformation. The analysis result after data transformation showed that the factors $\mathrm{B}, \mathrm{C}, \mathrm{BC}, \mathrm{BD}, \mathrm{CD}$, $\mathrm{ABC}, \mathrm{ACD}$, and $\mathrm{BCD}$ were significant factors. Finally, the residual analysis was performed on the transformed model. According to figure 3(b), the model is verified by the normality, homogeneity of variance and independence, so the model was appropriate.

Next, in order to make the results applicable to buffer packaging design, the in-package test method will be adopted for the actual packaging experiment. In order to reduce experimental errors, the number of repetitions was set to 5. A total of 320 experiments were needed to collect the required data. 


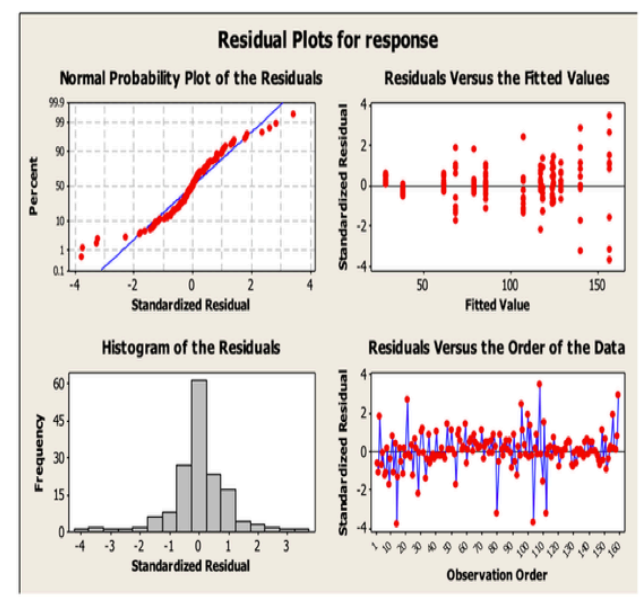

Figure 3 Residual analysis of the before transformation

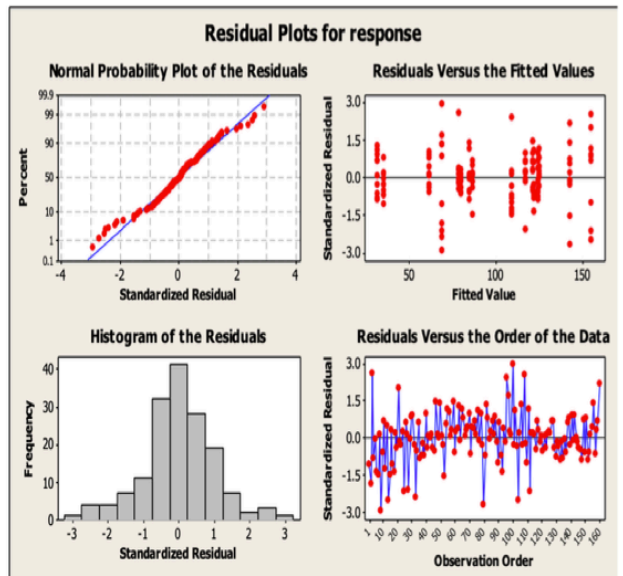

Figure 4 Residual analysis of the after transformation

Based on the collected data, the prediction model of impact strength is obtained through a regression analysis as follows:

$$
\begin{aligned}
\hat{y}_{G}= & e^{P} \\
P= & 6.14-0.0133 x_{b c}+0.00352 x_{a}-0.000017 x_{b^{2} c^{2}}+0.012 x_{b^{2}}+0.000009 x_{a b^{2} c} \\
& -0.000226 x_{a b c}-0.3 x_{b}-0.000151 x_{b^{3}}+0.000713 x_{a b}-0.00000001 x_{a^{2} b^{3}} \\
& +0.0015 x_{b c^{2}}-0.0000003 x_{a b^{2} c^{2}}-0.000363 x_{c^{3}}+0.000974 x_{a c}+0.00000015 x_{a^{2} b^{2}}
\end{aligned}
$$

\section{Discussion and Conclusions}

The actual product is based on the desktop PC mainframe as the test product and designs the bottom buffer packaging according to the accepted standards of mil-304c, CNS 10033 and customer requirements. According to the experimental data, the measured impact strength falls within $95 \%$ confidence interval of the estimated results, indicating that the established regression model can be used for packaging buffer.

Dynamic cushioning curves for packaging design staff, is beneficial information, not only can be used to choose the appropriate buffer material, thickness, area, and forecasts its buffering effect, but also can avoid using the method of trial and error is engaged in the packaging design. To shorten the packaging design schedule, cost, there is much help. However, in Taiwan, the limited test equipment and cost, is not widely used, more than the industry according to the experience by the method of trial and error for cushion packaging design.

The dynamic buffer curve can only determine the application interval of static stress, and it is impossible to estimate accurately. However, the trial and error method can only be used to determine whether the design conforms to the customer's requirements, and it is impossible to know whether the design is the most appropriate or not. The regression model established in this study can accurately estimate the optimal value of each condition so that an economical and reasonable buffer packaging can be designed to reduce the use of buffer materials and packaging costs effectively.

\section{References}

(1) Meidutè-Kavaliauskienè, I., Aranskis, A., \& Litvinenko, M. "Consumer satisfaction with the quality of logistics services. Procedia-Social and Behavioral Sciences", Vol. 110, p.330-340, 2014.

(2) Chen, M. C., Chang, K. C., Hsu, C. L., \& Xiao, J. H. "Applying a Kansei engineering-based logistics service design approach to developing international express services", International Journal of Physical Distribution \& Logistics Management, Vol. 45, No. 6, p.618-646, 2015.

(3) Rijk, R., \& Veraart, R. (Eds.). Global legislation for food packaging materials. John Wiley \& Sons, 2010.

(4) Watkins, T. Corrugated board packaging. In Packaging Technology, 240-261, 2012.

(5) Biancolini, M. E., \& Brutti, C. "Numerical and experimental investigation of the strength of corrugated board packages", Packaging Technology and Science: An International Journal, Vol.16, No.2, p.47-60, 2003.

(6) Biancolini, M. E. "Evaluation of equivalent stiffness properties of corrugated board. Composite structures", Vol.69, No.3, p.322-328, 2005.

(7) Biancolini, M. E., Brutti, C., \& Porziani, S. "Corrugated board containers design methods", International Journal of Computational Materials Science and Surface Engineering, Vol.3, N0.2, p.143-163, 2010. 
(8) Schueneman, H. H. "A comparison of three different cushion test methods. In Current Trends in Protective Packaging of Computers and Electronic Components", ASTM International, 1988.

(9) Guo, Y., Xu, W., Fu, Y., \& Wang, H. "Dynamic shock cushioning characteristics and vibration transmissibility of X-PLY corrugated paperboard", Shock and Vibration, Vol.18, No.4, p.525-535, 2011.

(10) Wickramasinghe, V. K. Dynamics control approaches to improve vibratory environment of the helicopter aircrew (Doctoral dissertation, Carleton University), 2013.

(11) Montgomery, D. C. Design and analysis of experiments. John wiley \& sons, 2017,

(12) Wang, Z. W., \& Sun, Y. C. "Experimental investigation on bending fatigue failure of corrugated paperboard. Packaging Technology and Science", Vol. 31, No. 9, p.601-609, 2018. 